\title{
Comportamentos de bullying e conflito com a lei
}

\author{
Bullying behavior and conflict with the law
}

\author{
Isabela ZAINE \\ Maria de Jesus Dutra dos REIS \\ Ricardo da Costa PADOVANI
}

\begin{abstract}
Resumo
Bullying define-se como uma forma de agressão física, psicológica ou sexual de caráter persecutório e repetitivo, geralmente envolvendo pares. Este estudo investigou comportamentos de bullying em 16 adolescentes do sexo masculino em conflito com a lei, que cumpriam medidas socioeducativas em regime de semiliberdade e liberdade assistida. Os dados foram coletados individualmente por meio de um questionário adaptado de conflitos na escola. Todos os participantes relataram terem sido vítimas ou autores de bullying ao menos uma vez no último ano. Observou-se maior incidência de autoria de bullying do que de intimidação por colegas, mostrando-se estatisticamente significativa ( $p<0,022)$. Participantes em semiliberdade relataram haver sido tanto alvo quanto autores de bullying em maior proporção do que os da liberdade assistida $(p<0,038)$. A intimidação não se restringia somente a colegas, mas generalizava-se a adultos. Resultados apontam a necessidade da investigação sobre a relação entre o comportamento de bullying e indivíduos infratores.
\end{abstract}

Unitermos: Bullying. Adolescentes em conflito com a lei. Relações com pares.

\begin{abstract}
Bullying is defined as a form of physical, psychological or sexual aggression which happens repeatedly and generally involves ones'peers. The present study investigated the occurrence of bullying behavior in 16 male young offenders attending a specialized institution (semi-detention and monitoredliberty). Data was collected individually by way of an adapted questionnaire about conflicts in school. All participants admitted to having been either a victim or perpetrator of bullying at least once during the lastyear. There was a greater incidence of bullying behavior as perpetrators than intimidation by colleagues, that was statistically significant $(p<0.022)$. Subjects under semi-detention have been shown to be perpetrators or targets of bullying in a greater proportion than those under monitored liberty $(p<0.038)$. Intimidation was not restricted to peers, but it was generalized towards adults. The results indicated the necessity for research into the relationship between bullying behavior and the behavior of criminal offenders.
\end{abstract}

Uniterms: Bullying. Teenader conflict with the Law. Peer relations.

A violência, cujos episódios podem ser definidos como atos com o objetivo de ferir ou prejudicar outro indivíduo física ou psicologicamente, é um fenômeno de múltiplas topografias (Orpinas \& Horne, 2006; Sá \& Werlang, 2007) e comportamentos antissociais, como danos ao patrimônio, conflitos

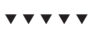

1 Universidade Federal de São Carlos, Departamento de Graduação em Psicologia. Rod. Washington Luís, km 235 - SP-310, 13565-905, São Carlos, SP, Brasil. Correspondência para/Correspondence to: I. Zaine. E-mail: <isabela_zaine@yahoo.com.br>.

Agradecimentos: Aos Salesianos, que consentiram a realização da pesquisa, e às unidades de Liberdade Assistida e Semiliberdade, que permitiram a coleta de dados. 
interpessoais e atos criminosos (Lopes Neto \& Saavedra, 2003).

O fenômeno chamado bullying ou intimidação por colegas ou pares é usualmente encarado como um subtipo de violência, sendo definido como uma forma de agressão em que um ou mais indivíduos ameaçam outros física, psicológica e/ou sexualmente de maneira repetida por um período determinado de tempo (Batsche \& Knoff, 1994). Assim, suas principais características são intencionalidade do ato, ocorrência por tempo prolongado e desequilíbrio de poder físico, psicológico ou social entre os indivíduos (Orpinas \& Horne, 2006; Pinheiro, 2006).

Episódios de bullying classificam-se em diretos e indiretos. As ações diretas podem ser físicas - chutar, empurrar, bater, tomar pertences - ou verbais - insultos e apelidos ofensivos. Já as indiretas são aquelas que fazem com que alguém seja discriminado ou excluído de seu grupo social, como disseminação de boatos ou histórias desagradáveis sobre um indivíduo (Lopes Neto \& Saavedra, 2003; Pinheiro, 2006).

Tradicionalmente, estudos acerca desse fenômeno (Heinrichs, 2003; Olweus, 1978, 1993; Smith, 2002) têm sido desenvolvidos levando-se em conta o ambiente escolar: um dos locais que mais proporciona interações entre pares. No entanto, o fenômeno não necessariamente se restringe a esse contexto, podendo incluir qualquer ocasião em que se observe intenção de maltratar uma pessoa e colocá-la sob tensão. Qualquer que seja o contexto ou as relações envolvidas, o bullying tem várias facetas: a dos alvos, a dos autores (bullies) e a das testemunhas.

Os alvos podem ser passivos ou provocativos (Batsche \& Knoff, 1994; Olweus 1978): os primeiros não revidam às provocações e não se defendem, tendendo a ser isolados, tímidos, passivos e com baixa autoestima (Heinrichs, 2003); já os provocativos apresentam temperamento explosivo e revidam às provocações (Batsche \& Knoff, 1994). Ambos os tipos de alvos são, em geral, fisicamente menores que seus intimidadores (Heinrichs, 2003).

Autores de bullyingsão frequentemente caracterizados pela impulsividade, forte desejo de dominar os outros e pouca empatia com relação aos alvos. Geralmente são mais fortes e maiores que seus alvos, possuem temperamento explosivo, baixa tolerância à frustração, são agressivos, desafiantes, opositivos e relativamente populares (Heinrichs, 2003). Não necessariamente se restringem à intimidação de seus pares, podendo intimidar todas as pessoas que eles acreditam que não poderão ou não irão revidar, ou aqueles com quem a intimidação foi satisfatoriamente realizada no passado.

Testemunhas possuem função de audiência para o autor de bullying, servindo-lhe como importante fonte de reforços e atribuindo-lhe statuse poder. Elas podem ter dificuldade de intervir em favor dos alvos por medo de retaliações ou de tornarem-se alvos. Além disso, podem se sentir coagidos a sucumbir à pressão do autor e participar do ato (Heinrichs, 2003).

Estudos acerca das implicações do bullying (Kumpulainen \& Räsänen, 2000; Olweus, 1993) revelaram que indivíduos que apresentaram comportamentos de bullying na infância e adolescência tiveram maior probabilidade de serem condenados, mais tarde na vida, por crimes graves, e de apresentarem reincidência criminal. Além disso, podem engajar-se em comportamentos de abuso de substâncias, relações negativas com pares, delinquência e envolvimento com gangues, depressão, ideação suicida e violência doméstica (Heinrichs, 2003).

Nessa direção, autores de bullying e jovens em conflito com a lei possuem muitos padrões de comportamento em comum. Além das já mencionadas características apresentadas pelos autores de bullying, os adolescentes em conflito com a lei persistentemente violam normas e regras sociais, comportando-se de maneira desviante das práticas culturais vigentes. Eles possuem dificuldades de socialização; apresentam uso precoce de tabaco, drogas e bebidas alcoólicas; envolvem-se em brigas e se associam com pares desviantes, constituindo gangues; não costumam demonstrar sentimento de culpa; são hostis; revelam precário controle das frustrações; agem sob controle das consequências imediatas; apresentam baixa empatia, promiscuidade sexual e crueldade contra animais; têm baixo rendimento acadêmico e tendência ao abandono escolar (Fite, Colder \& O'Connor, 2006; Gomide, 1999; Kauffman, 2001; R. Loeber \& M. S. Loeber, 1998; Padovani, 2003, 2008; Padovani \& Williams, 2005; Patterson, Reid \& Dishion, 1992; Reid \& Eddy, 2002). 
Considerando-se a relevância social de estudos que contribuam com a descrição do fenômeno de bullying, a relativa escassez de estudos brasileiros nessa área que envolvam mais do que o ambiente da escola e sua típica população, o presente estudo teve como objetivo investigar a ocorrência de comportamentos de bullying em uma população de adolescentes em conflito com a lei que estavam cumprindo diferentes medidas socioeducativas.

\section{Método}

\section{Participantes}

Fizeram parte do estudo 16 adolescentes do sexo masculino na faixa etária entre 13 e 19 anos (média de idade $=16,06$; desvio-padrão=1,57). Desse contingente, oito cumpriam medidas socioeducativas em regime de semiliberdade e oito em liberdade assistida em uma cidade do interior do Estado de São Paulo.

\section{Instrumentos}

A coleta de dados ocorreu em salas destinadas a atividades psicopedagógicas das instituições em que os jovens se encontravam para o cumprimento das medidas impostas.

Como instrumento, utilizou-se uma adaptação do questionário de conflitos na escola de Pinheiro (2006) para a população de adolescentes em conflito com a lei. O instrumento apresentava brevemente a definição de bullying e os objetivos da pesquisa e era composto por duas partes: a parte "A" continha 15 questões que procuravam verificar se os participantes haviam sido alvo de bullying no ambiente escolar e na comunidade durante o último ano; a parte "B" continha 15 questões que verificavam comportamentos de autoria de bullying no mesmo período.

As questões eram fechadas e abrangiam bullying verbal ( $\mathrm{n}=9$ ): "Algum colega te xingou, fez brincadeiras de mau gosto a seu respeito, ou te provocou de um jeito ofensivo?", bullying indireto ( $n=2)$ : "Colegas disseram mentiras ou espalharam rumores falsos a seu respeito e tentaram fazer com que os outros não gostassem de você?" e bullying físico ( $n=4)$ : "Alguém te bateu, chutou ou empurrou?". As questões eram respondidas numa escala likert de cinco pontos; as respostas poderiam corresponder a "nenhuma vez","1 ou 2 vezes no último ano","2 ou 3 vezes por mês","1 vez por semana" ou "várias vezes por semana".

\section{Procedimentos}

O estudo foi aprovado pelo Comitê de Ética de instituição de ensino público, com Protocolo SISNEP $n^{\circ}$ 3235.0.000.135-08, parecer n 460/2008, em 19/12/2008. Todos os participantes e seus responsáveis legais assinaram o Termo de Consentimento Livre e Esclarecido antes do início da coleta.

O instrumento foi aplicado individualmente em uma sala que garantisse privacidade. Como alguns dos participantes tinham dificuldades em ler com fluência, as instruções e as questões eram lidas a eles pela pesquisadora. Participantes tinham em posse uma cópia do instrumento e podiam acompanhar e conferir a leitura das questões. As respostas ao questionário e aos relatos espontâneos foram registradas no próprio instrumento. As entrevistas duraram, em média, 40 minutos. Ao término do procedimento, os adolescentes voltavam às suas atividades cotidianas na instituição.

\section{Resultados}

Os resultados apontaram que $100 \%$ dos participantes admitiram haver sido tanto alvo quanto autores de bullying, ao menos uma vez, no último ano. Uma comparação entre o total das categorias "alvo" e "autor" de bullying, independentemente do regime de liberdade, mostrou que os garotos apresentaram frequência significativamente maior de comportamentos de intimidar pares do que relatos de serem alvos de colegas (Wilcoxon, $z=-2,297, p<0,022$ ). A média para a categoria "alvo" foi 3,75, enquanto a da categoria "autor" foi de 4,81 , sendo essa diferença estatisticamente significativa. Como os participantes estavam cumprindo medidas socioeducativas em diferentes regimes (semiliberdade e liberdade assistida), foi realizada uma comparação entre autoria e alvo de bullying, levando-se em conta essa particularidade. A Figura 1 representa a média para as categorias "alvo" e "autor" de bullying para todos os participantes (geral) e separadamente para os diferentes regimes de liberdade. 
As médias de autoria de bullying (5,9 para semiliberdade e 3,6 para liberdade assistida) foram maiores do que as de alvo de bullying (4,2 para semiliberdade e 3,3 para liberdade assistida), independentemente do regime de liberdade, seguindo a mesma direção da análise do grupo como um todo. Contudo, os participantes em regime de semiliberdade admitiram haver sido tanto autores quanto alvos de bullying em uma proporção maior do que aqueles em regime de liberdade assistida (Mann-Whitney, $z=-2,06, p<0,038$ ).

Ainda na Figura 1, a média da frequência de autoria de bullying foi significativamente maior do que a de ser alvo para os adolescentes em semiliberdade

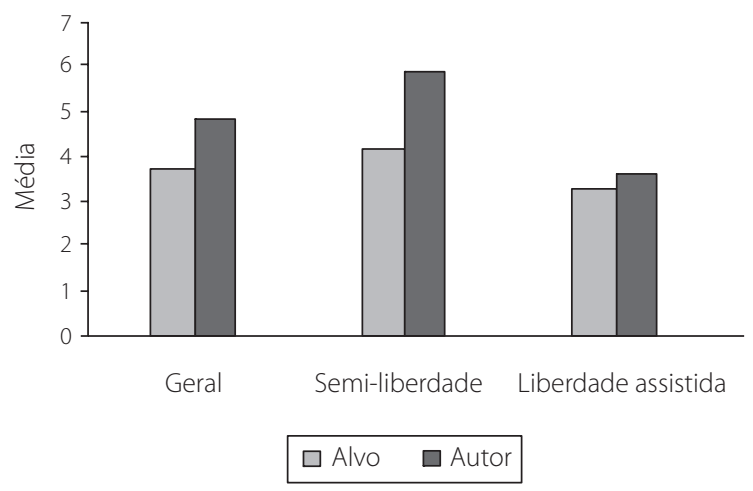

Figura 1. Média "alvo" e "autor" de bullying para os participantes como um todo (geral) e separadamente para os regimes de semiliberdade e liberdade assistida.

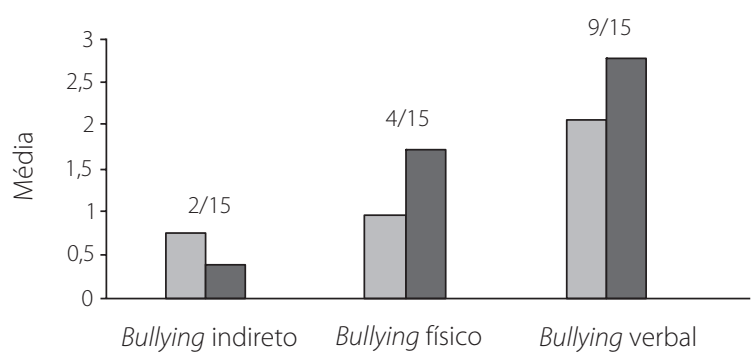

Tipo de bullying

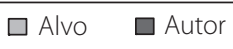

Figura 2. Média dos participantes para as categorias "alvo" e "autor" de bullying indireto, físico e verbal.

Nota: Os números acima das barras indicam número de questões por 378 categoria de bullying no instrumento.
(Wilcoxon, $z=-2,200, p<0,028$ ). Embora os participantes sob regime de liberdade assistida também apresentem uma média maior de autoria, essa diferença não se mostrou estatisticamente significativa (Wilcoxon, $\mathrm{z}=-0,707$, $p<0,480)$.

Com relação ao bullying físico e verbal, foi observada maior proporção de relatos de autoria de bullying do que de alvo. As médias obtidas para alvo e autoria de bullying físico foram 0,94 e 1,7, respectivamente; para bullying verbal as médias foram de 2,06 (alvo) e 2,75 (autor). Essa tendência não se manteve para o bullying indireto, sendo a média para a categoria "alvo" de 0,75, enquanto a da categoria "autor" foi igual a 0,37 (Figura 2).

Uma análise sobre o conteúdo do questionário e os comportamentos específicos apresentados nas questões revelou que participantes foram mais alvos de ameaças físicas individuais (56,25\%), de rumores falsos espalhados a seu respeito (56,25\%), ameaças físicas com objetos $(43,75 \%)$ e de xingamentos e brincadeiras desagradáveis (43,75\%). Já os comportamentos de autoria de bullying mais relatados foram agredir fisicamente colegas com chutes e empurrões (81,25\%), "xingar" efazer brincadeiras desagradáveis a outros (62,5\%) e ameaçar de maneira física um colega (56,25\%). A Tabela 1 resume os comportamentos avaliados e a porcentagem de participantes que relatou haver sido alvo ou autor de tais ações.

Dois comportamentos apresentam frequência zero (0) de autoria: espalhar rumores falsose discriminação racial. Particularmente com relação a espalhar rumores, alguns dos comentários informais levam os autores a acreditarem que o item foi visto pelos participantes como uma característica de informante; "fofocar"entendido como delatar ou "caguetar"; a ausência desse tipo de relato pode estar relacionada ao fato de esse comportamento ser recriminado entre indivíduos envolvidos em atos criminosos.

Embora a maioria dos participantes relatassem fazer e/ou receber insultos verbais, na maior parte das vezes não consideraram esses insultos como ofensivos, apesar de seu caráter persecutório e repetitivo. Participantes relataram encarar esses insultos como "brincadeira" ou "zueira", no entanto admitiram que algumas vezes essas "brincadeiras" culminavam em lutas corporais (Tabela 1). 
Tabela 1.Porcentagem de participantes que relatou "alvo" e "autoria" de bullying em comparação com os diferentes tipos de comportamentos avaliados.

\begin{tabular}{|c|c|c|c|}
\hline \multirow{2}{*}{ Tipo de Bullying } & \multirow{2}{*}{ Comportamentos } & \multicolumn{2}{|c|}{$\%$} \\
\hline & & Alvo & Autoria \\
\hline \multirow[t]{9}{*}{ Verbal } & Xingamentos e brincadeiras desagradáveis & 43,8 & 62,5 \\
\hline & Discriminação racial & 0 & 0 \\
\hline & Ameaças escritas/telefone/Internet & 0 & 18,8 \\
\hline & Apelidos & 31,3 & 37,5 \\
\hline & Piadas a respeito de características físicas & 0 & 0,6 \\
\hline & Piadas a respeito de roupas & 12,5 & 0,6 \\
\hline & Ameaças físicas individuais & 56,3 & 56,3 \\
\hline & Ameaças físicas grupais & 18,8 & 43,8 \\
\hline & Ameaças físicas com objetos & 43,8 & 43,8 \\
\hline \multirow[t]{2}{*}{ Indireto } & Isolamento social & 18,8 & 37,5 \\
\hline & Disseminação de rumores falsos & 56,3 & 0 \\
\hline \multirow[t]{4}{*}{ Físico } & Chutes, empurrões & 50,0 & 81,3 \\
\hline & Apropriação de bens & 31,3 & 12,5 \\
\hline & Agressão física grupal & 12,5 & 43,8 \\
\hline & Agressão física com objetos & 0 & 31,3 \\
\hline
\end{tabular}

Tabela 2. Relatos de bullying de participantes em Regime de Semiliberdade (SL) e Liberdade Assistida (LA) com distinção de categorias "alvo" e "autor" de bullying.

\begin{tabular}{lccl}
\hline \multirow{2}{*}{ Natureza do comportamento } & \multicolumn{2}{c}{ Participantes } & Relato \\
\cline { 2 - 3 } & SL & LA & \\
\hline Alvo & P1, P5 & P8 & Agressão física com pedras e pau. \\
Autor & P7 & P11 & Ameaça com arma de fogo. \\
& P3, P7 & & Ameaça com arma de fogo \\
& P3 & & Espancamento de conhecido (provocando morte) \\
& P5 & Agressão a colega com arma branca - faca
\end{tabular}

Tabela 3. Relatos de participantes em Regime de Semiliberdade (SL) e Liberdade Assistida (LA) de situações em que foram alvo de intimidação por adultos e/ou autores de intimidação dirigida a adultos.

\begin{tabular}{|c|c|c|c|}
\hline \multirow{2}{*}{ Natureza do comportamento } & \multicolumn{2}{|c|}{ Participantes } & \multirow{2}{*}{ Relato } \\
\hline & SL & LA & \\
\hline \multirow[t]{9}{*}{ Alvo } & P4 & & Ameaças e agressões físicas cometidas pelo padrasto \\
\hline & P5, P7 & P9, P12 & Agressão física cometida por policiais \\
\hline & P5 & & Agressão física por funcionários de instituições correcionais \\
\hline & & P9 & Discriminação racial por policiais \\
\hline & & P10 & Agressão física por professor \\
\hline & P1, P2 & $\mathrm{P} 12$ & Uso de arma de fogo em assalto \\
\hline & P3 & & Intimidação (em grupo) da polícia com armas brancas \\
\hline & P4 & & Agressão fatal ao padrasto com arma branca (faca) \\
\hline & P7 & & Disparo de arma de fogo contra devedor de dinheiro (tráfico) \\
\hline \multirow[t]{3}{*}{ Autoria } & P8 & & Uso de arma de fogo para intimidação em cobrança de dívida (tráfico) \\
\hline & P8 & & Uso de armas brancas em cobrança de dívida (tráfico) \\
\hline & & & $\begin{array}{l}\text { Agressão física em grupo a adulto desconhecido com arma branca } \\
\text { (pau) }\end{array}$ \\
\hline
\end{tabular}


Observa-se que os comportamentos de bullying dos quais os participantes declaram ser alvo apresentam topografia semelhante ao tipo de bullying que implementam. Todos os relatos incluíam ameaças à integridade física deles próprios e de outros e, em muitos desses relatos, objetos eram utilizados com esse propósito (Tabela 2).

Dos relatos, $75 \%$ corresponderam a participantes em regime de semiliberdade e $25 \%$ àqueles em liberdade assistida. Além de os indivíduos em semiliberdade emitirem e serem alvos mais frequentemente de comportamentos de bullying, esses comportamentos tendem a ser mais graves e fisicamente nocivos.

Os relatos feitos pelos participantes, contudo, não se restringiram a intimidações dirigidas a pares ou realizadas por eles, mas incluía agressões envolvendo adultos. Há categorias de relatos em que os participantes eram alvo de agressões realizadas por adultos ou autores de agressões dirigidas a adultos (Tabela 3). Dentre os episódios que envolveram intimidação por adultos, verifica-se que todas as agressões partiram de figuras de autoridade, por exemplo, padrasto, policial, agente penitenciário e professor.

Com relação à autoria de intimidação de adultos pelos adolescentes, observa-se que todos os relatos envolveram utilização de armas brancas ou de fogo ou de instrumentos que pudessem ferir. A intimidação de adultos foi majoritariamente relatada pelos participantes em regime de semiliberdade $(68,7 \%)$ em comparação aos garotos da liberdade assistida (31,3\%).

\section{Discussão}

A pesquisa confirma resultados encontrados em trabalhos anteriores (Fante, 2005; Lopes et al., 2003; Pinheiro, 2006), nos quais o bullying aparece como uma realidade no cenário brasileiro atual e presente em nossa sociedade. No cômputo geral, observou-se que os adolescentes em regime de semiliberdade apresentaram uma maior frequência de relatos de autoria de bullying do que aqueles sob medida de liberdade assistida.

É interessante observar como alguns comportamentos de bullying não são vistos como agressivos ou danosos. Especificamente no que concerne a xingamentos, insultos e apelidos de mau gosto, os participantes encararam esse tipo de comportamento como brincadeiras, mesmo que desencadeassem agressões físicas em altas proporções. Seria interessante que novas pesquisas se dedicassem a investigar as razões pelas quais esse tipo de agressão não é sequer notada pelos jovens em conflito com a lei, bem como verificar se esse padrão se mantém em populações que não estão cumprindo medidas socioeducativas.

Um desafio significativo para uma pesquisa como esta é manter o relato verbal próximo da realidade, sem distorções produzidas por medo da autoridade e da divulgação das informações voluntariadas. Dessa forma, parece interessante notar como os participantes, particularmente aqueles sob o regime de semiliberdade, relataram vários comportamentos agressivos passíveis de pena, mesmo quando afirmavam que esses comportamentos estavam menos frequentes no período da medida socioeducativa. Foi possível observar que algumas dessas descrições pareciam acontecer com frequência entre seus pares. Considerando esses elementos, levantamos a suposição de que o relato dos comportamentos agressivos, pelo menos durante o período de reclusão penal, parecia elevar o status do adolescente, levando-o a ter alguns privilégios, inclusive respeito e medo por parte dos pares. Já os adolescentes que não estavam em regime de reclusão pareciam evitar falar mais abertamente sobre atos de violência. Não podemos afirmar se a omissão desse relato seria resultado da real ausência de comportamentos agressores no repertório do adolescente ou se seria uma forma de evitar possíveis punições.

Como apontado anteriormente, participantes em regime de semiliberdade relataram uma diminuição nos episódios de bullying (autoria e alvo) no período de internação. Essa diminuição era reputada, por alguns, como produto direto do medo das punições relacionadas ao "mau comportamento", da possibilidade de terem como consequência direta não poder visitar a família no fim de semana ou ser transferido para instituições de reclusão por tempo integral, por exemplo. Dessa forma, a diminuição do comportamento agressivo parecia ser mais consequência das punições imediatas impostas pela instituição do que de uma reavaliação de conduta. Nessa condição, pode-se supor que, na ausência de uma agência de controle, o risco de reincidência pode ser elevado. 
A intimidação realizada pelos participantes não se restringia somente a pares, mas se estendia a adultos. Estudos anteriores (Batsche \& Knoff, 1994) revelaram que o sucesso na intimidação de um tipo de população específica pode acabar se expandindo a outras populações à medida que o intimidador se torna mais eficaz. Dessa forma, podemos supor que uma vez que esses jovens se tornaram eficientes em intimidar colegas e se associaram em atividades ilegais, esse comportamento pode ser generalizado a diferentes grupos sociais.

Em geral, os participantes relataram mais comportamentos dos quais eram autores do que alvo de intimidações. Contudo, o relato também mostra, como previsto pela literatura, que os participantes foram intimidados por figuras paternas e/ou de autoridade (Baldry, 2003; Batsche \& Knoff, 1994). As agressões são típicas daquelas evidenciadas em relações onde se estabelece desequilíbrio de poder (Orpinas \& Horne, 2006; Pinheiro, 2006).

O acesso permitido pela instituição e a liberdade para coleta de dados foi um importante avanço tanto de pesquisa quanto de intervenção. De fato, embora o número de participantes pareça pequeno, a amostra contou com uma porcentagem representativa dos jovens que estavam cumprindo pena naquele momento nas instituições investigadas. Estudos posteriores deveriam se dedicar a ampliar o número de participantes para que os resultados possam ser generalizáveis a outras populações e outras regiões do país.

Um passo importante, no futuro, será adicionar ferramentas de investigação sobre estilos parentais e exposição à violência intrafamiliar, uma vez que pesquisas anteriores (Baldry, 2003; Batsche \& Knoff, 1994) demonstraram que muitos dos autores de bullying provêm de lares com pais autoritários ou de estilo parental inconsistente.

Estudos têm apontado uma maior probabilidade de autores de bullying se envolverem em comportamentos infratores mais graves e serem criminalmente condenados na vida adulta (Batsche \& Knoff, 1994; Heinrichs, 2003; Kumpulainen \& Räsänen, 2000). Na população avaliada, podemos identificar que os adolescentes que cometeram crimes mais graves também apresentavam um relato de maior frequência de bullying. Seria interessante investigar futuramente se o bullying seria um precursor do comportamento infrator ou se sua ocorrência aumentaria com o aparecimento ou fortalecimento de atos infracionais graves. Para tanto seria interessante investigar o comportamento de bullying apresentado por essa população durante a infância e início da adolescência, por meio de diferentes fontes de informações, sejam sociais (pais, professores, colegas, irmãos, dentre outros), sejam documentais (registros escolares, registro em delegacias de menores, laudos profissionais, diários etc.).

Os resultados parecem apontar que a gravidade e a frequência dos comportamentos de bullying e dos atos infracionais coexistem intimamente. Endereçar as variáveis envolvidas em comportamentos violentos sempre representa um desafio; contudo, acreditamos que o bullying precise ser diretamente tratado pelos órgãos institucionais relacionados à educação, seja ela a educação formal representada pelas escolas, seja a educação prevista pelas instituições responsáveis pela aplicação das medidas socioeducativas.

Dessa forma, será de importância crucial investigar e implementar medidas de intervenção eficazes para diminuir a ocorrência desse fenômeno e capacitar os profissionais de diferentes instituições a identificar e interferir no problema. Além disso, seria interessante desenvolver programas de intervenção que levem em conta as especificidades dessa população (Cortez, Padovani \& Williams, 2005; Padovani, 2008; Patterson et al., 1992). Intervir precoce e eficientemente na redução de comportamentos de bullying poderia implicar a prevenção de comportamentos violentos, transgressores e criminosos a longo prazo.

\section{Referências}

Baldry, A. C. (2003). Bullying in scholls and exposure to domestic violence. Child Abuse \& Neglect, 27 (7), 713-732.

Batsche, G. M. \& Knoff, H. M. (1994). Bullies and their victims: understanding a pervasive problem in the schools. Schools Psychology Review, 23 (2), 165-174.

Cortez, M. B., Padovani, R. C., \& Williams, L. C. A. (2005). Terapia de grupo cognitivo comportamental com agressores conjugais. Estudos de Psicologia (Campinas), $22(1), 13-21$

Fante, C. (2005). Fenômeno bullying: como prevenir a violência nas escolas e educar para a paz. São Paulo: Verus.

Fite, P. J., Colder, C. R., \& O'Connor, R. M. (2006). Childhood behavior problems and peer selection and socialization: risk for adolescent alcohol use. Addictive Behavior, 31 (8), 1454-1459. 
Heinrichs, R. R. (2003). A Whole-school approach to bullying: special considerations for children with exceptionalities. Intervention in School and Clinics, 38 (4),195-204.

Gomide, P. I. C (1999). Menor infrator: a caminho de um novo tempo. Curitiba: Juruá

Kauffman, J. M. (2001). Characteristics of emotional and behavioral disorders of children and youth ( $7^{\text {th }} \mathrm{ed}$.). Englewood Cliffs, N. J.: Merril Prentice Hall.

Kumpulainen, K., \& Räsänen E. (2000). Children involved in bullying at elementary school age: their psychiatric symptoms and deviance in adolescence - an epidemiologiocal sample. Child Abuse \& Neglect, 24 (11), 1567-1577.

Loeber, R., \& Loeber, M. S. (1998). Development of juvenile aggression and violence: some common misconceptions and controversies. American Psychologist, 53 (2), 242-259.

Lopes Neto, A. A., \& Saavedra, L. H. (2003). Diga não para o bullying. Rio de Janeiro: Abrapia.

Olweus, D. (1978). Agression in the schools: bullies and whipping boys. Washington, DC: Hemisphere Press.

Olweus, D. (1993). Bullying in schools: what we know and what we can do. London: Blackwell.

Orpinas, P. \& Horne, A. M. (2006). Bullying prevention: creating a positive school climate and developing social competence. Washington, DC: American Psychological Association.

Padovani, R. C. (2003). Resolução de problemas com adolescentes em conflito com a lei: uma proposta de intervenção. Dissertação de mestrado não-publicada, Universidade Federal de São Carlos.
Padovani, R. C. (2008). Resolução de problemas sociais com adolescentes em conflito com a lei: estratégias de mensuração e intervenção. Tese de doutorado não-publicada, Universidade Federal de São Carlos.

Padovani, R. C., \& Williams, L. C. A. (2005). Proposta de intervenção com adolescentes em conflito com a lei: um estudo de caso. Interação em Psicologia, 9 (1), 117-123.

Patterson, G. R., Reid, J. B., \& Dishion, T. J. (1992). Antisocial boys. Oregon: Castalia.

Pinheiro, F. M. F. (2006). Violência intrafamiliar e envolvimento em "bullying" no ensino fundamental. Dissertação de mestrado não-publicada, Universidade Federal de São Carlos.

Reid, J. B., \& Eddy, M. (2002). Interventions for antisocial behavioral: overview. In J.B. Reid, G.R. Patterson \& J. Snyder. Antisocial behavioral and adolescents. A developmental analysis and model for intervention (pp.195-201). Washington: American Psychological Association.

Sá, S. D., \& Werlang, B. S. G. (2007). Homícidio seguido de suicídio na cidade de Porto Alegre. Estudos de Psicologia (Campinas), 24 (2), 181-189.

Smith, P. K. (2002). Intimidação por colegas e maneiras de evitá-la. In, E. Debarbieux \& C. Blaya. Violência nas escolas e políticas públicas. Brasília: Unesco.

Recebido em: 22/6/2009

Versão final reapresentada em: 18/2/2010

Aprovado em: 19/3/2010 